Escribir canciones, recordar y seguir adelante

La música como posibilidad comunicativa para el cambio social

Begoña Quintero, Carlos Arango

Extensión en red, (12), e023, 2021

ISSN 1852-9569 | https://doi.org/10.24215/18529569e023

http://perio.unlp.edu.ar/ojs/index.php/extensionenred

FPyCS | Universidad Nacional de La Plata

La Plata | Buenos Aires | Argentina

\title{
Escribir canciones, recordar y seguir adelante
}

\author{
La música como posibilidad comunicativa para el cambio social \\ Write Songs, Remember and Move on \\ Music as a Communicative Possibility for Social Change
}

\author{
Begoña Quintero' Carlos Arango² \\ labegoquintero56@gmail.com carango@uco.edu.co \\ https://orcid.org/0000-0002-2039-5578 https://orcid.org/0000-0002-2120-3304 \\ 1 Alcaldía La Ceja Del Tambo | Colombia \\ 2 Universidad Católica de Oriente | Colombia
}

\begin{abstract}
Resumen
El artículo muestra una experiencia de investigación-creación en la que se convocó a jóvenes víctimas del conflicto en la región del Oriente de Antioquia, en Colombia, a escribir canciones en las contaran sus vivencias personales. Una vez conformado el grupo, se brindó una formación en técnica vocal, canto, escritura de canciones e interpretación, basada en los principios de la comunicación para el cambio. Luego de exponer la experiencia, se realiza un balance desde las canciones que surgieron en el proceso y se analiza la potencialidad que tiene la música como posibilidad de cambio social.
\end{abstract}

\section{Palabras clave}

música, cambio social, investigación-creación, conflicto

\section{Abstract}

The article shows a arts-informed research experience, in which young victims of the conflict in the eastern region of Antioquia, Colombia, were summoned to write songs where the would tell their personal experiences. Once the group was formed, training was provided in vocal technique, singing, song writing, and interpretation, based on the principles of communication for change. After exposing this experience, a balance is made from the songs that emerged in the process and the potential of music as a possibility of social change is analyzed.

\section{Keywords}

music, social change, arts-informed research, conflict 


\section{Introducción}

La música siempre ha sido un medio de comunicación. Para Daniel Levitin (2019), esto se explica desde la evolución: la música permitió compartir conocimientos, consolidar lazos de amistad y de amor, manifestar la tristeza y la alegría, y establecer una relación trascendente y espiritual. Según el autor, hay que entender cómo los modos musicales -que él denomina canciones- sirvieron para resolver problemas de la especie, y que si persisten hasta la actualidad es porque en la adaptación al entorno fue útil expresarse musicalmente.

Pero si la música puede entenderse como comunicación (Arango \& Rojas, 2019), vale preguntarse cómo entenderla en clave de comunicación para el cambio social. Partiendo de los postulados propuestos por Alfonso Gumucio Dragón (2016), por José Miguel Pereira (2010) y por Luis Ramiro Beltrán (2006), la comunicación permite a los grupos sociales una serie de elementos que impulsan el cambio social. Estos elementos son la posibilidad del diálogo y la participación, y mediante ellos las comunidades pueden escucharse, reconocerse, interpretar sus realidades y proponer caminos para cambiar aquello que de su situación actual podría ser mejorado.

Todas esas características se pueden cumplir a través de la música y en la historia se pueden rastrear numerosos antecedentes (Fisher, 2018). Puede citarse como ejemplo la revolución de los años sesenta (Gil Calvo, 2001), donde la música actuó como un catalizador mediante el cual una generación entera pudo resignificar su mundo y crear alternativas de cambio. En el caso de Colombia, las músicas populares sirvieron para reivindicar unas maneras particulares de ser que se alejaban de los parámetros europeos racionalistas (Parra Valencia, 2017).

En ese contexto, este proyecto tuvo como propósito inicial pensar la comunicación como una alternativa para hacer investigación-creación y para realizar procesos comunicativos desde la forma de hacer música, en este caso, con jóvenes del Oriente antioqueño ${ }^{1}$ que vivieron el conflicto armado en la región, para permitirles disponer de herramientas tendientes a crearla y a interpretarla en el marco de sus procesos de cambio personal y social. La región donde se realizó el proyecto, ubicada en el oriente del Departamento de Antioquia, Colombia, sufrió diversas escaladas de violencia, relacionadas, principalmente, con la incursión de actores armados al margen de la ley (guerrillas y grupos paramilitares) debido al interés estratégico que esta región representa en términos geográficos: embalses 
generadores de energía para el país, la autopista que conecta a Medellín, capital del departamento, con Bogotá, la capital del país, así como el aeropuerto internacional José María Córdova, que conecta a Medellín con el resto del mundo.

El proceso, desarrollado entre 2013 y 2017, se inició con la convocatoria a jóvenes que hubieran sido víctimas del conflicto armado y que estuvieran interesados en escribir y en grabar canciones para tramitar sus duelos mediante la música. La convocatoria se hizo desde Family Production, un centro de creación y de producción musical especializado en el género urbano, ubicado en Rionegro, Antioquia, Colombia.

Como gestores/as de este proyecto, los/as autores/as participamos en la convocatoria a los/as jóvenes; en la formación para escribir, para cantar y para interpretar sus canciones; en la coordinación de la producción musical; y en la difusión de los track una vez que estuvieron listos, así como en todo el proceso de documentación, de sistematización de la experiencia y de comprensión como proceso investigativo/creativo, del cual este artículo es un producto. En la experiencia, siempre estuvo presente el interés por reconocer la comunicación como eje articulador de las vivencias que se generaron. En este trabajo, el propósito es compartir esa experiencia con sus detalles formativos y comunicativos, a fin de que se pueda emplear como referente de investigación-creación en otras iniciativas sociales que busquen en la música una forma de promover el cambio social.

En este artículo, se exponen los conceptos fundamentales del marco referencial que se usó para orientar la experiencia, se muestran las fases en las que se ejecutó el proceso y se propone una reflexión sobre la música como potenciadora del cambio social.

\title{
Música y comunicación
}

\author{
Las artes son particularmente herramientas de comunicación para las personas, \\ así como la lectura y la escritura [...], lenguajes que ofrecen nuevas posibilidades \\ y alternativas de comprensión de la vida; medios de comunicar ideas \\ que tienen el objetivo de enriquecer la calidad de vida, \\ y de canalizar y transformar la agresividad del hombre. \\ Fundación La Barca (Mejía Betancur, 2014, p. 65)
}

Para Ramón Andrés (2008), la música ha estado presente desde la existencia del ser humano. Desde sus inicios, el hombre ha hecho uso de la música en una forma social; y aunque en la era prehistórica no existía una concepción concreta sobre la música como tal, se hacía uso de sonidos que conformaban una manera de comunicación. Sin embargo, 
con la evolución humana el significado de la música, y todo lo que ello abarca, se ha ido definiendo de manera específica, hasta llegar a constituirse en una pieza primordial para la forma de vida social de la humanidad. De ahí que sea relevante analizar la conformación de la música en sus funciones sociales, y entender de qué manera es utilizada para lograr ciertos objetivos dentro de determinados procesos sociales, de forma que todo ello genere un cambio dentro de una comunidad o de un territorio.

La música ha alcanzado un nivel de masificación y de propagación mayor que cualquier otra expresión cultural, lo que le permite establecerse como un canal que va más allá de la apreciación valorativa y de la diversión; la música se convierte en un medio de transmisión de ideas y de ideologías que dotan de sentido al mundo social actual, tal como lo discutiera Theodor Adorno (2009).

Con la conformación de sociedades más complejas y con la llegada de los medios masivos de comunicación, la música vivió una expansión sin precedentes. Actualmente, nuestra idea de música está permeada por esas mediaciones, por lo cual es importante entender que así como la comunicación no se circunscribe a los medios masivos (Galindo Cáceres, 2008; Montoya Gallego, 2018), la música no se limita a la música comercial difundida en forma masiva. $\mathrm{Y}$ es justo esa diferencia la que permite hablar de la música como posibilitadora del cambio social; es otra comunicación (alternativa a la masiva) la que se requiere para generar procesos de cambio en las comunidades.

Del mismo modo, es otra música la que se requiere para cantar los conflictos que han vivido los/as jóvenes que participan en este proyecto. Y es que la música y los géneros que la componen adquieren mayor o menor importancia de acuerdo al contexto social que predomine, el cual está predeterminado por factores económicos, culturales, políticos y religiosos. Por lo tanto, su concepción y la importancia que esta pueda tener en la vida de las sociedades varían en torno a los valores del grupo social.

Tal como lo enunciaba Aristóteles, la música representa las pasiones o el estado del alma (Adorno, 2009). Con medios masivos o sin ellos, esta afirmación mantiene su vigencia, ya que por medio de la música se expresa y, por tanto, se comunica lo que se vive en un territorio (Arango \& Rojas, 2019). Podríamos decir que por medio de la música una comunidad se ve representada conforme lo que vive, y es reflejada en sus letras y en sus musicalizaciones: carga simbólica que conforma la fuerza comunicativa.

Por esta razón, la música también se constituye en una función formativa, al ser acatada como una disciplina. En la antigua Grecia, la música era considerada parte esencial en el desarrollo integral de cada persona, convirtiéndose en un elemento constitutivo del 
proceso de socialización (Andrés, 2008). De ahí que autores como María del Mar y Bernabé Villodre (2012) muestren a la música como un medio de comunicación, gracias a la riqueza que aporta desde la creación de líricas hasta la ejecución de melodías que forman un determinado género $y$, a su vez, por la creatividad que implica. A esto se suman las razones por las cuales es necesario escribir mediante recursos como rimas, sinónimos, narración de experiencias y construcción de metáforas, todo lo cual, consideramos, hace parte del proceso comunicativo involucrado en la música.

En efecto, si se considera que comunicarse tiene que ver con la interrelación entre agentes de producción y consumo de contenidos, la decodificación por medio de la música se podrá desarrollar en mejores condiciones, pues al ser parte intrínseca de la sociedad la música permite la apropiación de manera más accesible que cualquier otro método para una efectiva comunicación. No en vano, desde el cine a la publicidad, pasando por los entornos públicos y privados, la música acompaña constantemente la vida de los seres humanos en la contemporaneidad.

Pero lo que decimos de la música aplica al arte. Todo proceso artístico se convierte en un medio de comunicación de las emociones de los/as creadores/as, de lo que estos/as viven dentro de su comunidad y de lo que desde allí se puede crear; el arte proporciona una perspectiva de cómo las personas asumen y comunican sus propias percepciones, sus maneras de responder y la comprensión del mundo que logran en su interacción con los demás.

Entonces, vista como posibilidad de cambio social, la música en tanto forma de comunicación aporta numerosos elementos. Así, para que la música pueda convertirse en medio de comunicación para el cambio social, debe tenerse en consideración su carácter creativo: siempre que el arte es la generación de visiones alternas de la vida, escribir canciones, hacer música envuelve un proceso estético y discursivo que se evidencia en la construcción de letras, en la definición de bases musicales armónicas y rítmicas, en las elaboraciones melódicas y en las construcciones tímbricas. Arte, comunicación y creación se fusionan en el proceso de la música como fenómeno comunicativo en el ámbito social.

En suma, desde la evolución de nuestra especie (Levitin, 2019), desde la parte étnica (Parra Valencia, 2017) y desde la masificación de las músicas populares (Arango \& Rojas, 2019), es evidente que la música se puede entender desde la comunicación. En la medida en que creadores/as y escuchas pueden abordar asuntos personales y sociales a través de ella, la música es un lenguaje potencialmente abierto a la expresión de todo tipo de sentires y de sucesos. 


\section{Cambio social}

El cambio social es una necesidad constante. Las sociedades son dinámicas, como las personas que las conforman, por lo que de manera permanente deben adoptar sistemas de transformación que les permitan mejorar sus condiciones. En ese proceso, la comunicación es clave, porque permite tejer los puentes de interacción mediante los cuales se construyan los consensos sobre los cuales va a girar el cambio. Dicho de otra forma, la comunicación permite a los actores sociales darle significado a las cosas que son relevantes para el grupo, trazar pautas de acción conjunta y retroalimentarse durante el avance en el proceso.

Gumucio Dragón (2001) menciona cinco características que están presentes en los procesos de comunicación para el cambio social: participación comunitaria y apropiación, lengua y pertinencia cultural, generación de contenidos locales, uso de tecnología apropiada, convergencia y redes. Desde el terreno del arte, Liliana Patricia Mejía Betancur (2014), destaca estas últimas, por su capacidad de promover los procesos (más que los instrumentos) y de fortalecer redes mediante el intercambio.

Lo anterior entra en relación con la intervención cultural abordada por Paulo Freire (1979), en la cual sustenta una pedagogía en la que el individuo aprende a cultivarse a través de situaciones de la vida cotidiana, que le aportan experiencias útiles para generar situaciones de aprendizaje. No se trata de una pedagogía para el oprimido, sino, por el contrario, del oprimido; el sujeto debe construir su realidad a través de las circunstancias, pero no para adaptarse sino para reformar la misma vida.

Vista desde el cambio social, la comunicación debe reafirmarse como camino hacia los procesos de transformación y, para esto, debe apoyarse en procesos educativos. El cambio implica, en primer lugar, reconocer que este se necesita porque una vieja forma de hacer o de entender las cosas ya no funciona en el marco de una comunidad. En segundo lugar, supone el diálogo que facilite una lectura conjunta de los factores que hacen que dichas maneras de hacer las cosas ya no son funcionales para los propósitos colectivos. Por último, requiere de idear estrategias para movilizar los cambios, de trazar planes de trabajo conjunto tendientes a movilizar el cambio deseado. Lo educativo, por tanto, integra parte fundamental, pues el cambio exige de adquirir nuevos aprendizajes y de desaprender viejos paradigmas.

Son herramientas de corte comunicativo las que hacen esto posible, ya que permiten reflejar en las comunidades empoderamiento, a partir de dar significado a las acciones y de posibilitar la búsqueda de bienestar, la recuperación de la identidad y el fortalecimiento 
de la memoria colectiva. Ahora bien, esta pedagogía social, necesaria para el cambio, implica procesos de comunicación de alto impacto y recordación en las personas. El empoderamiento, la reconfiguración de la memoria y la recuperación de las identidades implican modos de comunicar alternativos que generen impacto en las personas de una comunidad. La comunicación que simplemente dice lo que hay que hacer se convierte en información, se traduce en mandatos o en imposiciones para las personas. En otras palabras, es importante qué decir y cómo decirlo. $Y$, en ese sentido, el arte y, particularmente, la comunicación, tienen mucho por aportar.

Para lograr el proceso de un verdadero cambio social y, por lo tanto, de reconstrucción del tejido social, es provechoso retomar a Gumucio Dragón (2001) cuando señala la importancia de lograr cambios significativos desde la construcción de lo social, a partir de priorizar lo humano desde la apropiación de contenidos. Esta es una de las características propuestas por el autor que Mejía Betancur (2014) recalca desde la dimensión artística. Los contenidos circulan como referencias sobre el mundo, pero su apropiación por parte de las comunidades implica un proceso de recepción. Según estos estudios (Galindo Cáceres, 2008), en el terreno de la apropiación de los mensajes hay un amplio universo de posibilidades. Las personas no hacen suyos los mensajes como un acto mecánico, por lo que interpretarlos supone acercarlos a sus maneras de ser.

Al respecto, la música ofrece un acercamiento más emotivo que racional, más desde lo lúdico que desde lo institucional y más desde la vivencia personal que desde las visiones hegemónicas. Por ello, puede ser un canal sumamente efectivo para comunicar mensajes de cambio. Como propone Gumucio Dragón (2001), exteriorizar la problemática propia, establecer vínculos comunitarios y ser protagonista del propio cambio -en otras palabras, actuar desde lo endógeno y no desde lo exógeno-, altera positivamente las posibilidades del cambio social. Así como la comunicación, la música abre espacios de diálogo como un ejercicio colectivo basado en las dinámicas de la comunidad, a fin de generar el empoderamiento al que hemos aludido.

\section{Música y cambio}

Para Gino Stefani (1998), «vivimos sumergidos en un océano de sonidos» (en PalomaresMoral, 2004, p. 14). Cuando se trata de dar respuesta al concepto de música y al sentido que esta tiene en la cotidianidad de las personas -en sus vidas y en la sociedad en generalno se puede dejar de considerar que la música está organizada como un lenguaje que nos 
permite expresarnos. Un lenguaje, como sostiene Levitin (2019), afincado en estructuras cerebrales configuradoras de lo humano y gracias al cual creamos, hacemos, escuchamos, experimentamos y recreamos música. Desde allí, se sugiere la idea de cómo la música puede permitirnos evocar, describir, representar, relatar hechos y razonar acerca de ciertas situaciones. Cantar, tocar en grupo, animarse en público a la música son procesos de comunicación, de suerte que todos estos rasgos nos permiten entender que la música también funciona como medio de comunicación.

Este medio de comunicación es relevante en lo personal y en lo social. Y es esa relevancia lo que le confiere un enorme poder aglutinador. La música es una creación social. El ser humano determinó el significado de la música para sí, pero parece ser que ahora es la propia música la que le determina un significado; y esto se produce a través de procesos comunicativos mediante los cuales se dan a conocer las dinámicas de una comunidad en un territorio, donde por medio de letras, de melodías y de estructuras musicales se logra transformar el entorno y dar forma a un verdadero cambio.

En ese sentido, la masificación de la música permitió elevar a una escala mayor algo que ya estaba en nuestra memoria como especie. Desde el inicio de la evolución misma del ser humano, la música ha facilitado procesos de cambio y de estabilización de los comportamientos individuales y sociales. Porque es en ese punto de intersección entre lo individual y lo social que la música es posible. Como lenguaje, permite compartir códigos comunes; como medio de expresión masificado en las sociedades modernas, permite compartir memorias colectivas; y como contenido expresivo, permite manifestar emociones individuales y sentir empatía cuando la escuchamos.

Desde ahí, podemos retomar las ideas de Gumucio Dragón (2001, 2016) y la recontextualización que realiza Mejía Betancur (2014) en el terreno del arte. En ese puente que une lo individual y lo colectivo se hacen posibles la participación comunitaria, la generación y la apropiación de contenidos locales, la práctica de una lengua común y los vínculos de pertinencia cultural. Adicionalmente, algo muy importante para el presente trabajo es la buena sincronización de la música con la tecnología: desde su origen, los instrumentos musicales han empleado los conocimientos tecnológicos más avanzados de las diferentes civilizaciones. Como lo demuestra Berdard Sève (2018), el diseño, la ejecución y la mejora continua de los instrumentos musicales son procesos donde lo técnico y lo social se fusionan hasta perder sus límites. Esto es sincrónico con lo expresado por Sergio Roncallo-Dow (2011), quien sostiene que desde la mano hasta el lenguaje las invenciones técnicas han perseguido pautas de interacción social: pistas de construcción de sentido. 
En síntesis, la música puede contribuir al cambio social, primero, porque es un medio de comunicación, como vimos en la primera parte. Segundo, porque hace disponibles las emociones en las personas $\mathrm{y}$, desde ese lugar, es posible activar la participación comunitaria, generar y apropiar los contenidos producidos por los propios grupos sociales y fortalecer el uso de un lenguaje común. La suma de todo esto potencializa el sentimiento de pertenencia.

Sobre la base de lo expuesto hasta aquí, relataremos la experiencia que se vivió en el proceso de creación y de interpretación de canciones como forma de elaborar los recuerdos que dejó el conflicto en los/as jóvenes que participaron del proyecto [Tabla 1].

\section{Metodología}

Este es un proyecto de investigación-creación, lo que implica una aproximación al tema de estudio diferente a la que ofrecen los métodos de investigación convencionales, lo cual se debe a dos características. Por un lado, como señalan Gabriel Alba y Juan Guillermo Buenaventura (2020), el acercamiento del/la investigador/a al tema no se basa en la división sujeto-objeto de investigación; por el otro, los procesos de construcción del conocimiento son co-ocurrentes. «Esto quiere decir que, debido al carácter mixto y complejo de los problemas indeterminados, asumidos desde un contexto real, es posible obtener artefactos teóricos resultado de la investigación y artefactos empíricos resultado de la investigación» (Maestría en Diseño para la Innovación Social de la Universidad de Nariño, 2019, p. 3).

Para este trabajo, esto tiene dos consecuencias. En primer lugar, el proceso de investigación fue creciendo en la medida en que se avanzaba en la ejecución. De hecho, la primera formulación fue la del proyecto artístico y fue durante su ejecución que surgieron claridades sobre el proceso investigativo. En segundo lugar, la consideración de la idea de artefacto; por el lado musical, tanto las canciones creadas como la metodología desarrollada (convocatoria, proceso formativo en la escritura de canciones y en la interpretación musical, y proceso de producción musical); por el lado investigativo, la sistematización de la experiencia y su recuperación mediante un texto que ingrese a las dinámicas de la publicación académica. En este sentido, el artículo en sí mismo es un artefacto, puesto que pretende abrir la experiencia al conocimiento de otros/as investigadores/as-creadores/as para generar nuevas posibilidades en otras latitudes. 
De esta manera, el propósito de emplear la música como medio de comunicación para el cambio social se realizó mediante la convocatoria, la formación y la producción musical con los/as jóvenes. A partir del marco referencial expuesto, se diseñó un proceso de formación en composición de letras y en canto. La convocatoria se hizo a partir de las redes sociales de los/as autores/as y de la red de contactos de los/as artistas de [Family Production].

Población: jóvenes que vivieron la desaparición forzada de sus padres y sus hermanos/as, violaciones, asesinatos y situaciones que el conflicto generó en la región.

Muestra: jóvenes que empezaron el proceso (seis en total), con quienes se inició la formación a través de los módulos que se diseñaron para tal fin. La investigadora los acompañó como formadora en cada uno de ellos: en el proceso de escritura de las canciones, en la búsqueda de los registros para interpretarlas y en la grabación en estudio.

Una particularidad de estos procesos es su informalidad, precisamente por la resistencia que muchos/as jóvenes manifiestan ante la institucionalidad. Por esta razón, no se llevaron registros precisos de la asistencia, aunque era frecuente que la participación fuera intermitente. La razón general que podemos aducir sobre la deserción se relaciona con motivos laborales, pues las notables precariedades económicas hacen que la oportunidad de empleo, generalmente en otra ciudad, prevalezca sobre la creación artística.

\begin{tabular}{|c|c|c|c|c|c|}
\hline $\begin{array}{c}\text { NOMBRE } \\
\text { REAL }\end{array}$ & $\begin{array}{c}\text { NOMBRE } \\
\text { ARTÍSTICO }\end{array}$ & EDAD & GÉNERO & $\begin{array}{c}\text { LUGAR } \\
\text { DE ORIGEN }\end{array}$ & $\begin{array}{c}\text { TIEMPO } \\
\text { EN EL PROCESO } \\
\text { DE LOS TALLERES }\end{array}$ \\
\hline $\begin{array}{l}\text { Dani } \\
\text { Alexander } \\
\text { Álvarez } \\
\text { Gómez }\end{array}$ & Dony Alva & $\begin{array}{c}33 \text { años } \\
\text { Adulto, según la } \\
\text { Constitución } \\
\text { Política de } \\
\text { Colombia }\end{array}$ & Masculino & $\begin{array}{c}\text { Sonsón } \\
\text { Desplazado. } \\
\text { Actualmente } \\
\text { vive en Rionegro }\end{array}$ & 2 años \\
\hline $\begin{array}{l}\text { Elkin } \\
\text { Danober } \\
\text { Tobón } \\
\text { Sánchez }\end{array}$ & Crazzy & $\begin{array}{c}26 \text { años } \\
\text { Joven, según la } \\
\text { Constitución } \\
\text { Política de } \\
\text { Colombia }\end{array}$ & Masculino & $\begin{array}{c}\text { La Ceja } \\
\text { del Tambo } \\
\text { Violencia, } \\
\text { asesinato } \\
\text { de su padre, } \\
\text { delincuencia social }\end{array}$ & 1 año \\
\hline $\begin{array}{l}\text { Heider } \\
\text { González }\end{array}$ & $\begin{array}{c}\text { Heider } \\
\text { González }\end{array}$ & $\begin{array}{c}30 \text { años } \\
\text { Adulto, según la } \\
\text { Constitución } \\
\text { Política de } \\
\text { Colombia }\end{array}$ & Masculino & $\begin{array}{c}\text { El Carmen } \\
\text { de Viboral } \\
\text { Violencia } \\
\text { en el municipio } \\
\text { y sus alrededores }\end{array}$ & 6 meses \\
\hline
\end{tabular}

Tabla 1. Jóvenes que culminaron el proceso de los talleres formativos 
Durante el proceso, se llevó a cabo un proceso de registro fotográfico y audiovisual, que alimenta varios de los videos en los que se publicaron las canciones [Tabla 2]. Luego de la producción, se revisó el proceso completo y se elaboraron conclusiones desde la perspectiva de la comunicación para el cambio social que son expuestas en la sección correspondiente.

\section{Resultados}

Como resultados, tomamos tanto los obtenidos en el proceso de formación como las canciones que de este surgieron. Si bien las canciones producidas podrían tomarse como el resultado principal, desde la comunicación para el cambio asumimos algo más: la experiencia de la formación, las vivencias allí generadas y la forma en que los/as jóvenes transitaron el proceso, son parte constitutiva del proyecto y lo que desde este se puede compartir para otras iniciativas que utilizan la música como camino de cambio social.

Desde lo rastreado en el ámbito conceptual, destacamos la relación entre música y comunicación, y entre música y cambio social, a partir de las características enunciadas por Gumucio Dragón (2001). Desde esta perspectiva, diseñamos una formación que pasaba por lo vocal y que enfatizaba más el canto que la técnica propiamente dicha. El canto es una dimensión expresiva y comunicativa central en esta propuesta. Como mostraremos a continuación, se requiere de darle protagonismo a la propia voz y de entenderla como una forma de afirmar cosas en el mundo; en este caso, las vivencias de lo que, en primera persona, habría representado el conflicto. Las canciones destacan esa primera persona y la voz es el canal de comunicación que aparece en primer lugar.

La metodología que utilizamos en esta parte formativa se basó en los módulos teóricoprácticos de canto para la ejecución de letras y de canciones. Se trató de un programa formativo en el cual se revisaron los diferentes estilos del canto básico: pop, rock básico, balada, hip hop y estilos urbanos varios, entre otros. El principal objetivo fue abordar la voz como instrumento, cualidad imprescindible en el entorno juvenil, a través del trabajo de diversas facetas como respiración, colocación, emisión, extensión, tesitura, densidad y potencia de la voz.

En todo momento, se buscó eliminar el riesgo de lesión por sobreesfuerzo o mal uso, así como la cara más artística de esta disciplina, incidiendo en la interpretación y la expresión, por medio de la ejecución de letras que tuvieran relación con su experiencia vital y con la búsqueda de expresión hacia los demás. 
En el proceso se hizo énfasis en que los tecnicismos de la parte vocal tienen el sentido de lograr una expresión personal, lo cual no fue fácil para jóvenes que no contaban con entrenamiento musical. Las clases desarrolladas durante la formación, que se describen a continuación, fueron: Módulo 1. Técnica vocal básica, Módulo 2. Canto, Módulo 3. Ejecución de letras y Módulo 4. Interpretación de las canciones.

\section{Módulo 1. Técnica vocal básica}

El primer módulo abordó la técnica vocal, mediante el calentamiento corporal y vocal, la respiración, la resonancia y la resistencia (las tres $\mathrm{R}$ de la técnica vocal). No se trataba solo de abordar cómo escribir una letra y cómo contar una historia, sino de darles herramientas para que lo hicieran lo mejor posible, para que cuando fuéramos a hacer las grabaciones contaran con la técnica básica.

Aquí, enfatizamos la importancia de realizar el calentamiento vocal a menudo, para evitar lesiones o problemas que pueden desembocar en la pérdida total de la voz, en afonías, en nódulos, etc. Este módulo, no obstante, fue un espacio para reconocer la propia voz, para darle sonido musical a la primera persona, lo que se acerca a lo propuesto por Freire (1979): reconocerse y cultivarse.

Los ejercicios de calentamiento vocal se realizan con el objetivo de preparar y de poner a punto el sistema respiratorio, el sistema articulatorio, el aparato fonador y la caja de resonancia. Para llevar a cabo un buen calentamiento vocal, existen tres tipos básicos de ejercicios: estiramiento, respiración y vocalización.

Estiramiento: antes de hacer cualquier tipo de ejercicio, se deben estirar los músculos de la cara, el cuello y el diafragma. Se debe comenzar por el cuello, ${ }^{2}$ luego, siguen los estiramientos de cara ${ }^{3} \mathrm{y}$, finalmente, los ejercicios de cabeza y de cuello. ${ }^{4}$

Respiración: estos ejercicios pretenden un control máximo de la respiración, lo cual es muy importante a la hora de cantar, porque permiten aumentar la capacidad pulmonar, ventilar adecuadamente y concentrarse antes de una presentación. ${ }^{5}$

Vocalización: son ejercicios fundamentales porque ayudan a desarrollar y a acostumbrar la musculatura del cuerpo (labios, lengua, cuerdas vocales y velo del paladar). ${ }^{6}$

\section{Módulo 2. Canto}

Enfatizar en la comunicación implica centrar el proceso en los/as jóvenes como interlocutores, como partícipes de un tejido social. Por esto, la técnica vocal, abordada 
en el primer módulo, intenta hacerlos conscientes de cómo el propio cuerpo es una plataforma de comunicación. Sin embargo, para este proceso el canto es más importante que la técnica, porque en la dimensión del canto los conocimientos del propio aparato productor de sonidos, que se intenta controlar y aprender a explorar con los ejercicios anteriores, alcanzan un nuevo nivel: cantar.

En este módulo aparecen los ejercicios básicos que se utilizaron como pre-fonación, entonación, ejecución de canciones y vocalización básica; pero también era importante darles las herramientas dentro del canto para poder trabajar afinación, entonación y pistas para indagar cómo se cantan las canciones. Trabajamos con piano, para tener una referencia externa musical sobre la cual procurar los acercamientos de tono, e indagamos cómo se prepara una canción antes de cantarse: entramos en la interpretación.

Calentamiento de la voz y vocalización: calentar la voz es esencial para cantar sin desafinar y para aclarar la voz. Como complemento, se hacen ejercicios de vocalización que ayudan a explorar la capacidad para escucharse, algo muy importante para mejorar la práctica vocal.

Esto último es clave en la comunicación, y el módulo se abordó desde esa perspectiva: hacer música es un acto de escucharse en medio de otros que también están hablando, produciendo mensajes, por lo cual es fundamental reconocer el propio cuerpo como productor de sonidos y orientar ese autoconocimiento a la interacción con otros/as.

Nuevamente, aparece la importancia de diferenciar entre técnica vocal y canto. Por tanto, los ejercicios fueron dirigidos a desarrollar esas competencias.

Ejercicios de respiración: estos ejercicios también son imprescindibles: la respiración y la postura forman parte de los contenidos que se acostumbran en las clases de canto, porque ayudan a tomar conciencia del cuerpo, a relajarse, a reforzar el diafragma y a respirar desde el vientre.

Aprendizaje de las técnicas vocales: en el contexto del canto, estas técnicas se emplean para comenzar las exploraciones sobre la interpretación vocal. Esto exige el control del cuerpo, su reconocimiento como espacio comunicativo y la escucha. Gran parte del trabajo en las clases de canto fue enseñar las técnicas vocales básicas para controlar la voz y para desarrollar la interpretación vocal. De manera adicional, el canto exige dicción y pronunciación de las vocales, lo cual es decisivo para la entonación de frases y, en últimas, para que los/as oyentes puedan entender el mensaje que se quiere entregar mediante las canciones. 


\section{Módulo 3. Escritura de canciones}

En el tercer módulo experimentamos la escritura de letras. Fue un módulo muy bien recibido por los/as jóvenes, pues suponía entrar en la parte creativa. Al comienzo, hubo resistencias y bloqueos, pues en su imaginario escribir sugiere tener algo muy importante para decir. Los libros y las canciones más reconocidos entran a jugar un rol difícil, porque sugieren que para escribir se debe ser un sujeto especialmente talentoso. Sin embargo, una estrategia didáctica que funcionó fue tomar las canciones y analizarlas, identificar los mecanismos, las estrategias, los recursos con los cuales están hechas, para reconocer que si se conocen y se dominan ciertos recursos existen posibilidades de hacer canciones tan buenas como esas. En otras palabras, algo similar a la relación entre los módulos 1 y 2: primero reconocer, para luego aprender a explorar y a controlar.

Aquí, ya nos ubicamos más en la comunicación. No se trata únicamente de cantar bien o de hacerlo de una manera profesional; el punto es cómo interpretar la canción, es identificar las reglas que permiten escribir una canción, asunto que remarca el enfoque comunicativo que trabajamos en los diferentes los módulos. En este caso, los contenidos procuran una escucha diferente de canciones conocidas, como vía para reconocer los recursos que estas emplean. Bajo la premisa de que un mismo tema puede ser presentado de diferentes formas, en el módulo se abordaron cuatro formas de escribir una canción: historias, consignas, primera persona y descriptivas.

\section{Historias}

La canción cuenta una historia de un modo muy similar a un cuento: tiene un desarrollo, donde le ocurre algo a un personaje. Generalmente, narra la historia de una tercera persona y, como sucede con los guiones de cine, la historia suele tener un giro. Este tipo de canciones se caracterizan, además, por ser anecdóticas y cargadas de humor. Algunas incluyen una moraleja o una reflexión final. Ejemplos: Ricardo Arjona, «Historia de taxi»; Los Auténticos Decadentes, «La prima lejana»; Billo’s Caracas Boys, «Juanita bonita».

\section{Consignas}

La canción busca expresar una idea simple o una consigna, como puede ser un descontento o una queja, principalmente social. Por lo general, los versos son muy simples y se caracterizan por tener un estribillo muy fuerte donde se deja bien en claro la consigna, la queja o el leitmotiv de la canción. Este tipo de canciones también suelen usarse para la música dance, comercial o, en publicidad, para los jingles, puesto que el estribillo prima con su consigna sobre el resto de la canción. Ejemplos: Miguel Cantilo, «La marcha de la bronca»; The Beatles, «All you need is love»; El Combo de las Estrellas, «Plegaria vallenata». 


\section{Primera persona}

La canción está hablada en primera persona. El/la autor/a cuenta sus sentimientos, sus pensamientos o sus ideas desde su propio punto de vida. Si bien pueden contar una historia, este tipo de canciones se destacan por estar dirigidas a quien escucha; interpelan al oyente, lo exhortan a sentir algo, lo invitan, lo persuaden. Ejemplos: Fabulosos Cadillacs, «Vos sabés»; Ataque 77, «Amigo».

\section{Descriptivas}

La canción gira en torno a describir algo o a alguien; también puede ser un sentimiento, una emoción. Lo que destaca en este caso es el uso de metáforas y de metonimias, así como la descripción en detalle, precisa y lujosa. La canción no relata hechos sino que ofrece descripciones, y -sobre todo- interpretaciones de esas descripciones. Ejemplos: Ricardo Arjona, «Señora de las cuatro décadas»; La renga, «Caminito al costado del mundo».

Estas cuatro formas se pueden combinar. Pero el énfasis del módulo estuvo puesto en reconocer los caminos creativos que han empleado los/as compositores/as. Con esto, se pudo reducir la distancia que pudiera haber entre los/as jóvenes en su rol como oyentes y en su rol como creadores/as.

Aquí es donde la comunicación genera mucha fuerza: todos/as tenemos historias para contar. Las vivencias de cada cual son únicas y es desde ahí desde donde se puede explorar con mayor fortaleza el qué decir.7 De este modo, el módulo nos puso en la vibración de lo narrativo y lo descriptivo, y nos dio los elementos para facilitar el auto-reconocimiento y para empoderar a los/as jóvenes.

\section{Módulo 4. Interpretación de las canciones}

Cantar es transmitir; es un acto de comunicación entre el/la intérprete y el escucha. En el marco de nuestra experiencia, se trataba de que los/as jóvenes aprendieran a trabajar todos los elementos de la canción (texto, música y voz) y a valorar la importancia en su conjunto. Para esto, se trabajó la parte expresiva y el énfasis estuvo puesto en saber comunicar el significado de la letra, el contexto del personaje, sus conflictos y sus anhelos.

Los componentes de este módulo se orientaron a explorar la canción como un todo, como un mensaje comunicativo que surge de la mezcla de varios elementos. Al abordarlos por separado, logramos el reconocimiento de las partes en relación con el conjunto. 
El texto de la canción es fundamental. Leer el texto es la primera etapa a la que nos enfrentamos en el trabajo vocal. Debemos conocer las emociones, hacerlas nuestras y decidir qué queremos contar. El/la cantante debe comprender el significado completo de la composición, ese es el trabajo del/la intérprete. El texto delimita el mensaje que se quiere entregar en un sentido denotativo, implica la intención del/la autor/a, y esa intención es la que debería guiar la interpretación.

\section{Música}

La música es un lenguaje que permite al ser humano crear y producir sentido. Esta persigue suscitar una experiencia estética en quien la oye, expresar sentimientos, así como las circunstancias personales y colectivas. Por esto, saber cómo el ritmo, la armonía y la melodía se unen para crear sonidos articulados es una labor que requiere de trabajo como oyente. Se es músico luego de escuchar mucha música. Y es sobre esa base que luego aparecerá el texto, por lo cual escuchar y sentir la música es decisivo.

\section{Interpretación}

Interpretar es lograr que un contenido dado sea comprendido, traducido a una manera particular de expresión. En la expresividad juegan las sensibilidades que el músico pueda reconocer como el uso del cuerpo para darle forma a lo que la mente ideó. En la interpretación, se busca ser fiel al contenido original del mensaje interpretado. Y esto implica aportarle a esa expresividad, desde el cuerpo, la voz y las intenciones con las cuales se produce y se proyecta el sonido.

\section{Música y emociones}

Aprender a oír música en estilos y en géneros diferentes es clave aquí. La música despierta emociones. Gracias a ella, al sentirnos diferentes podemos hacer conscientes otras cosas, podemos animarnos o desanimarnos a algo. Por esto, además de los recursos, los elementos y las partes del cuerpo que participan en el canto, es útil asumirse como simple observador/a de lo que ocurre con la música cuando otros/as la interpretan o la oyen. Esta es una forma de ser más sensible al panorama de situaciones que mueve la música.

Este cuarto módulo asienta las posibilidades de la comunicación. Desde la comunicación, entendimos que el proceso de la interpretación permite conocer las emociones, hacerlas nuestras, decidir qué queremos contar, cómo se canta, y comprender el significado completo de la composición, que es el trabajo como tal del/la intérprete. 


\section{Balance del proceso}

En el proceso formativo, los contenidos y los ejercicios de los módulos procuraron el reconocimiento de los múltiples factores que intervienen en el hecho de cantar y de componer canciones. La parte de técnica vocal (módulo 1) sirvió para el reconocimiento del cuerpo como un espacio preparado para producir sonido. La parte de canto (módulo 2) alentó el uso del cuerpo como espacio musical. Ya no se trataba del sonido en sí mismo sino de convertirlo en música, a través del manejo del cuerpo. La parte de escritura (módulo 3), sirvió para reconocer elementos, estrategias y recursos en la creación de las letras, al tiempo que permitió explorar un propio lugar como persona con una historia que es parte de una historia colectiva. Finalmente, en la parte de interpretación (módulo 4) todos esos elementos se integraron como parte de un proceso comunicativo.

Una primera conclusión de esta parte es cómo el conocimiento sirve para empoderar y para tomar conciencia de sí mismos/as. Si bien los ejercicios prácticos exigían hacer cosas, ese hacer estaba dirigido a reconocerse. En ese sentido, el conocimiento (de las técnicas, los recursos, las emociones, las historias) impulsa el asumirse como parte de una historia colectiva que, en este caso, es la historia del conflicto.

Colombia ha sufrido de varias formas el conflicto. La violencia hace parte de su desarrollo como grupo social y esto marca las historias de vida de todos/as sus habitantes de diversos modos (Atehortúa Sánchez, 2017; Roncallo-Dow, Cárdenas \& Cruz-González, 2020). Por esa razón, encontrar en el arte una manera de expresar las emociones que ha desatado el conflicto es una manera de responsabilizarse.

Tener conocimientos sobre música puede ser entretenido para muchas personas. Pero en este caso iba más allá de lo lúdico. Estimular las facultades para producir y para mirar el arte como una experiencia de ideas fue sumamente significativo para nosotros/as. La interpretación se refiere a ese hecho que luego se convierte en un contenido. Ese contenido es la propia historia, y por eso la parte formativa de este proceso implicaba preguntarse cómo encarar la escritura y cómo interpretar la canción. De fondo, esto mueve preguntas profundas, relacionadas con la comunicación: cómo expresar el mensaje, cómo leer esa situación de conflicto que afecta en lo personal pero que hace parte de una historia común. Por eso, sobre todo al final de los módulos, cuando ya estábamos abocados a la escritura de las canciones y a la generación de las maquetas para iniciar las grabaciones, el cómo lo íbamos a expresar implicaba, también, preguntarse quién soy, qué quiero ser, cómo sueño que las personas que me están escuchando puedan pasar las situaciones y las adversidades que deben enfrentar. 
Como parte de este balance, debemos hablar del proceso y de los productos (las canciones). En cuanto al proceso, se resalta la voluntad de participación de los/as jóvenes. Desde la convocatoria, y desde su constancia en la formación, es necesario recalcar todo lo llamativo que resulta para ellos/as el poder hacer arte como una forma de expresarse. Medios como el grafiti (Hernández Hernández, 2018), el mural (González, Gómez Duque \& Restrepo, 2018) y la interpretación musical (Arango \& Correa, 2018; Castro Arango \& Quintero, 2018), son formas comunicativas que se registran en la región como potenciadoras de la capacidad expresiva de las personas. Los/as jóvenes son particularmente receptivos/as a este tipo de iniciativas.

Si bien el proceso formativo tiene sus propias exigencias, que en algunos momentos hacen decrecer el entusiasmo en los/as jóvenes, lo que fue ocurriendo durante la formación es de destacar: a su manera, cada uno/a fue apropiándose de los elementos conceptuales y encontrando su propia voz.

\section{Las canciones producidas}

En cuanto a los resultados, de los seis jóvenes que iniciaron, tres culminaron hasta llegar a la canción producida en estudio. El proceso de escritura fue liderado por cada uno, a partir de su propia historia, y apoyado en la parte lírica y musical por el equipo de trabajo de Family Production, que funciona como un laboratorio de expresión musical.

Las canciones exploran los géneros urbanos. Fusiones entre rap, salsa y lofi hacen parte de las sonoridades. En términos de los recursos, los más utilizados fueron la consigna y la narración de historia.

\begin{tabular}{|c|c|c|c|c|c|}
\hline CANCIÓN & ARTISTA & $\begin{array}{c}\text { NOMBRE } \\
\text { REAL }\end{array}$ & COMPOSITOR/ES & PRODUCCIÓN & ARREGLOS \\
\hline $\begin{array}{c}\text { La vida } \\
(2016)\end{array}$ & Dony Alva & $\begin{array}{c}\text { Dani } \\
\text { Alexander } \\
\text { Álvarez } \\
\text { Gómez }\end{array}$ & $\begin{array}{c}\text { Danny Andrés } \\
\text { García García } \\
\text { Dani Alexander } \\
\text { Álvarez Gómez }\end{array}$ & $\begin{array}{c}\text { Family } \\
\text { Production }\end{array}$ & $\begin{array}{c}\text { Danny Andrés } \\
\text { García García }\end{array}$ \\
$\begin{array}{c}\text { Guerrero } \\
\text { caído } \\
(2013)\end{array}$ & Crazzy & $\begin{array}{c}\text { Elkin } \\
\text { Danober } \\
\text { Tobón } \\
\text { Sánchez }\end{array}$ & $\begin{array}{c}\text { Elkin Danober } \\
\text { Tobón Sánchez }\end{array}$ & Producciones & Diomer Gómez \\
\hline $\begin{array}{c}\text { Juguetes } \\
\text { de guerra } \\
(2013)\end{array}$ & Dagh & Heider González & Danny Andrés \\
\hline
\end{tabular}




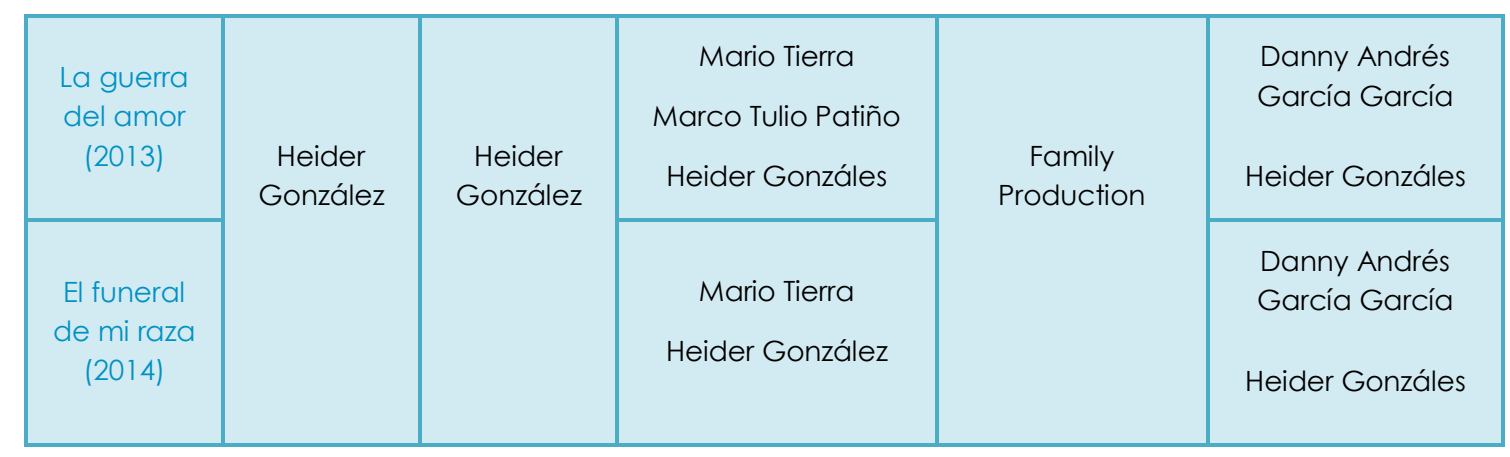

Tabla 2. Canciones producidas durante el proceso

«La vida» (2016) [Imagen 1], canción de Dani Alexander, explora el sentimiento de agradecer las enseñanzas familiares. «Papá de pequeño me decía: "Mira hijo cómo nos cambia la vida", y al pasar de tanto tiempo adquirí sabiduría». Luego agrega: «Y gracias al consejo hoy yo estoy aquí». En el coro, el autor ratifica que la vida es una y por eso hay que disfrutarla. Esa es la consigna que repite el coro a lo largo de la canción: «La vida se va, se va y se va, y nos deja tristezas, sentimientos que a mi alma llegan y en mi mente pesan».

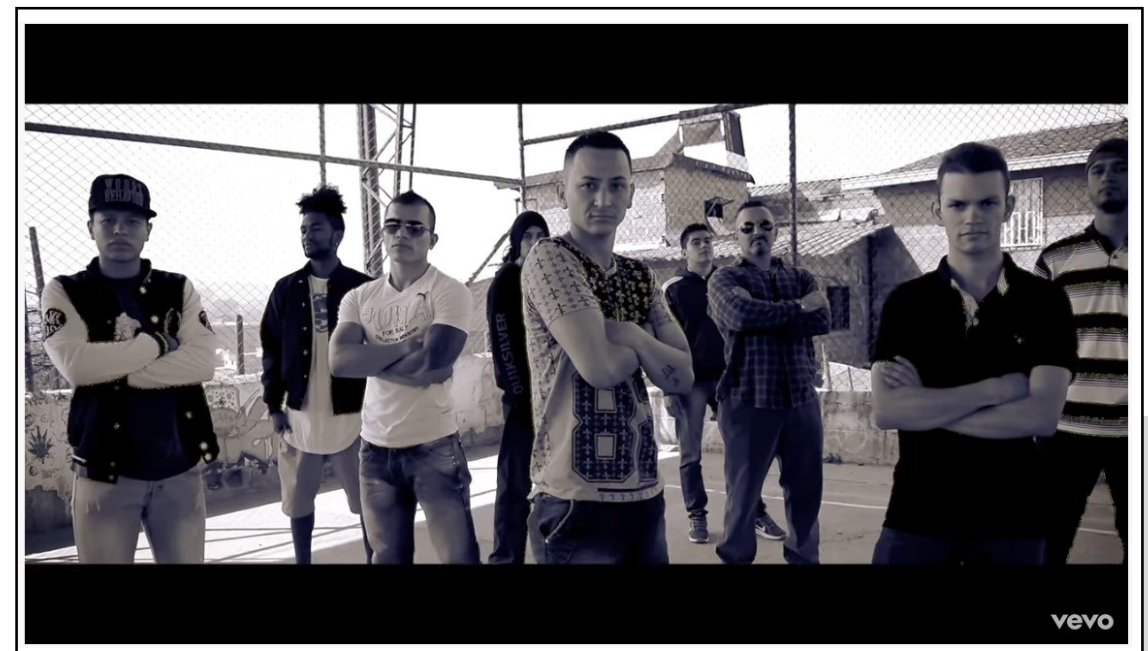

En «Guerrero caído» (2013) [Imagen 2], Elkin Danober cuenta la historia del asesinato de un amigo. Al amanecer de un fin de semana, «al parcero "Titi" le ha llegado su final». En el coro: «La vida me ha quitado más de lo que me ha dado, guerrero caído, mi alma ha tocado». En la segunda estrofa, el autor se adentra en las preguntas que este duelo le genera: «Primero fueron mis padres, ahora mi parcero, es un gran sufrimiento, no lo calma ni el dinero». En esas palabras, la letra mueve una reflexión en torno al valor de la vida y el lugar que ocupan las dificultades. Además, muestra su inconformidad por el rol pasivo de las autoridades, pues a su amigo lo asesinaron al lado del Centro de Atención Inmediata (CAI), ante la indiferencia de la policía. 


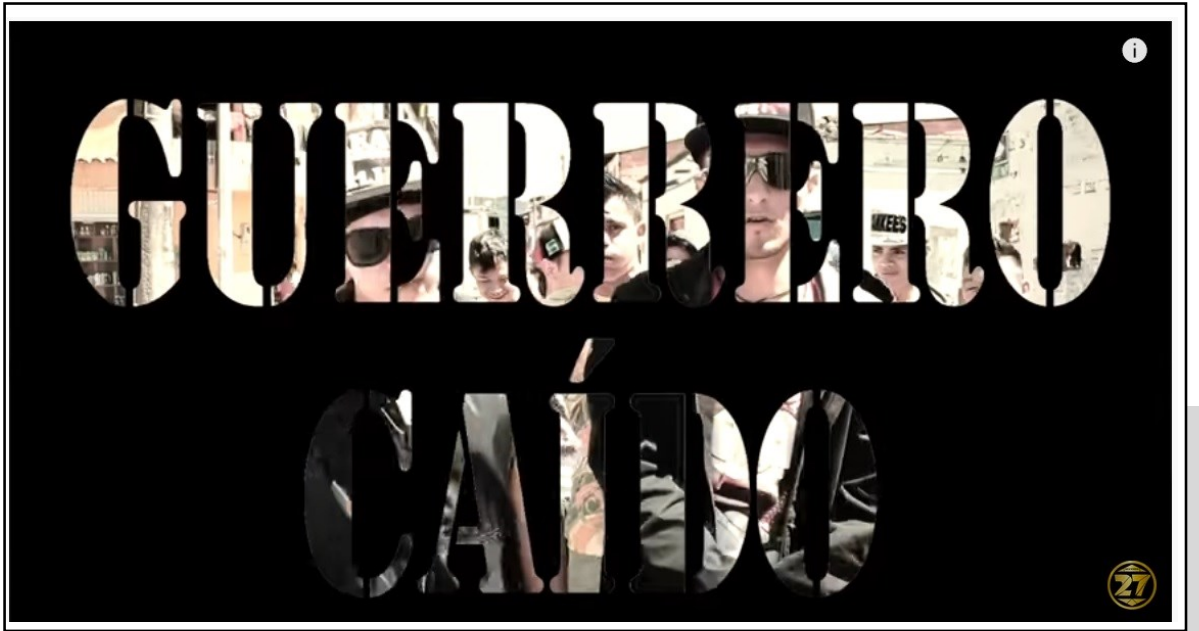

Imagen 2.

Crazzy, «Guerrero caído» (2013)

Fuente: Youtube

En «Juguetes de guerra» (2013), Heider González denuncia la explotación de los/as niños/as en la guerra: «Los niños de mi tierra ya son involucrados, arriesgando sus sueños para ser asesinados». La canción empieza con sonidos de telenoticieros sobre su participación en la guerra. En el coro, liderado por voces infantiles, se afirma: «Yo canto colombiano, no dejo de soñar un país que sin tierra se aprende a caminar, a diario lo luchamos, guerriando por la vida, los sueños nos escoltan en las balas perdidas». Y de esta forma, el autor explora los dolores que implica para las madres perder a sus hijos/as, y cuestiona por el futuro de un país que no respeta los sueños de los/as más pequeños.

En «La guerra del amor» (2013), Heider invita a todos a «prepararse para la guerra, la guerra del amor». Desde esa consigna, procura una resignificación de la guerra, con armas que «disparen alegría». En el coro, dice: «Dame la mano, guerrero hermano, luchemos juntos por nuestra paz, dispara arruyos, pan y caricias pa'que los niños no lloren más».

En «El funeral de mi raza» (2014) [Imagen 3], González narra la transformación del campo, donde las circunstancias obligaron a los/as campesinos/as a alzarse en armas. El texto cuenta cómo estas personas cambiaron las herramientas para cultivar la tierra por fusiles con los cuales luego les dispararon por la espalda. En el coro, enfatiza: «Así se cae mi casa, el tiempo no espera: pasa».

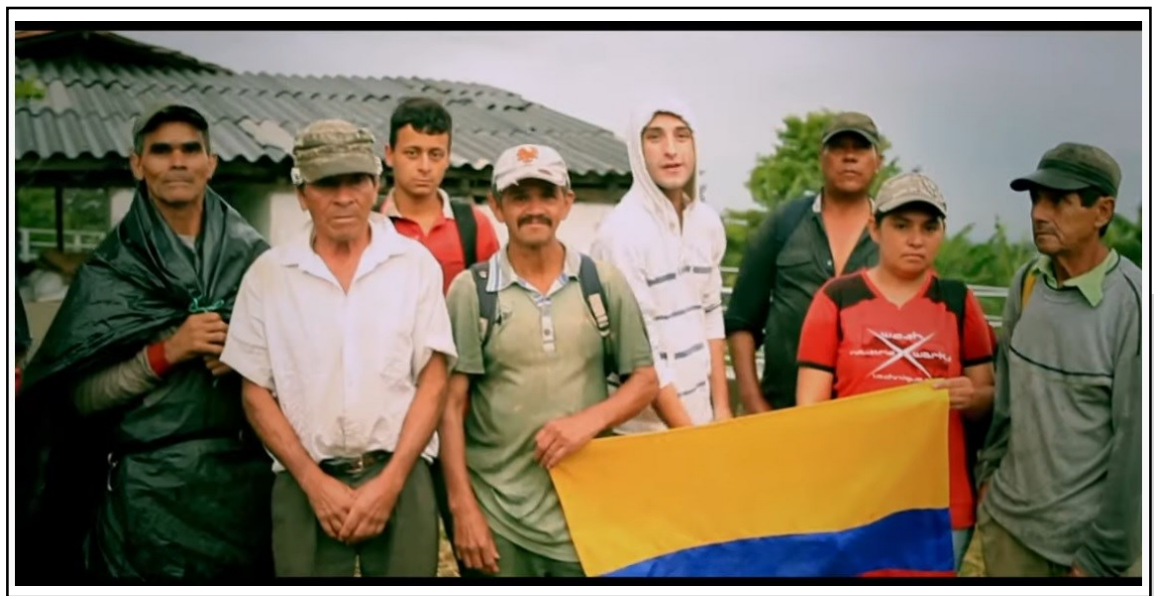

Imagen 3.

Heider González.

«El funeral de mi raza»

(2014)

Fuente: Youtube 
Llama la atención que el recurso más empleado fue la consigna, lo cual nos dice cómo el proceso de empoderamiento de la propia voz generó la fuerza suficiente para señalar las inconformidades. Si bien las historias y las declaraciones sobre los dolores emocionales aparecen, la consigna surge como una vía para declarar la postura propia ante los acontecimientos.

\section{Conclusiones}

La música es una plataforma clave para tramitar los dolores del conflicto. Esta permite a los/as autores/as expresarse, manifestar sus consignas y contar sus historias, describir las escenas de los barrios y hablar de los personajes que los habitan. Pero, además, permite a los/as escuchas identificarse, encontrar en sus propias memorias cosas parecidas, acontecimientos comunes que van marcando los lazos del tejido social.

La comunicación para el cambio le permite a la música un enfoque diferente. Ya no se trata de vender canciones o de adquirir fama o prestigio por ser cantante. El cambio implica la reflexión sobre las cosas que están mal y el reconocimiento de las emociones individuales y colectivas que se ven afectadas, estimuladas negativamente, por un contexto de guerra y de dolor. Sin embargo, hablar en primera persona es un primer paso al reconocimiento del lugar propio y a la construcción de lazos comunicativos.

La experiencia de este proyecto permite reconocer, primero, la importancia de la convocatoria a los/as jóvenes. En ella hay que resaltar que las canciones pueden ser una forma de asumirse como un sujeto histórico, co-responsable de lo que pasa con la propia vida. Segundo, el rol decisivo que tiene la formación. Esta permite generar un proceso, motivado por las sesiones, por los contenidos y por los ejercicios, que sirve como un proceso de preparación. Le da a la música, y particularmente al canto, un lugar destacado que merece preparación para estar a la altura del compromiso histórico que significa escribir canciones, grabar la voz e interpretar las historias. Tercero, todo el potencial que tienen experiencias como estas, donde los/as protagonistas de los hechos que más marcaron a un territorio son reconocidos en su individualidad, en su dolor y, desde allí, se los/as acompaña para que puedan alzar su propia voz.

Descubrir, experimentar y narrar pueden ser las palabras clave de este proceso. Descubrirse (reconocerse: como cuerpo que produce sonido y como mente que tiene memorias que pueden convertirse en música); experimentar la propia voz como un instrumento musical y de comunicación que tiene enormes potencialidades que se pueden 
ampliar a medida que se avanza en la formación y que se practican los ejercicios; experimentar desde lo creativo, mediante el empleo de diversos recursos para concretar el mensaje.

Hablamos de la relación entre música y comunicación como un laboratorio de creación para resignificar la memoria personal y colectiva. Hablamos de comunicación para el cambio. Esto es parte de lo que nos deja esta experiencia.

\section{Agradecimientos}

Ante todo, agradecemos a los jóvenes que participaron en el proceso, por su voluntad y su resiliencia. Al Sistema de Investigación, Desarrollo e Innovación de la Universidad Católica de Oriente, Antioquia, Colombia, y al semillero de investigación Música y Comunicación del programa Comunicación Social. A la empresa Family Production.

\section{Referencias}

Adorno, T. (2009) [1973]. Disonancias/Introducción a la sociología de la música. Madrid, España: Akal.

Alba, G. y Buenaventura, J. G. (2020). Cruce de caminos. Un estado del arte de la investigación-creación. Cuadernos del Centro de Estudios en Diseño y Comunicación, 79, 21-49. https://doi.org/10.18682/cdc.vi79.3675

Andrés, R. (2008). El mundo en el oído. El nacimiento de la música en la cultura. Barcelona, España, Acantilado.

Arango, C. y Correa, D. (2018). Oriente sonoro: tecnología e imaginarios de territorio a partir de las canciones. En C. Arango (Ed.), Desarrollo y territorio: comunidad, familia y educación (pp. 31-48). Rionegro, Colombia: Fondo Editorial Universidad Católica de Oriente.

Arango, C. y Rojas, B. (2019). Comunicación y música. Campos de tensión en la construcción de una industria creativa en el Oriente antioqueño, Colombia. Luciérnaga Comunicación, 11(22), 130-145. 
Atehortúa Sánchez, J. A. (2017). Aportes recientes en torno de las narrativas de las víctimas del conflicto armado. En C. Arango (Ed.), Desarrollo y territorio: humanidades para la paz (pp. 21-54). Medellín, Colombia: Fondo Editorial Universidad Católica de Oriente. Recuperado de https://bit.ly/39hpMKh

Beltrán, L. R. (2006). La comunicación para el desarrollo en Latinoamérica: un recuento de medio siglo. Anagramas, 4(8), 55-76. Recuperado de https://dialnet.unirioja.es/descarga/articulo/5181393.pdf

Castro Arango, S. y Quintero, A. (2018). Oriente sinfónico: procesos de interacción comunicativa en las bandas sinfónicas en el Oriente antioqueño. En C. Arango (Ed.), Territorio, identidades, comunicación (pp. 265-282). Medellín, Colombia: Fondo Editorial Universidad Católica de Oriente.

Del Mar, M. y Villodre, B. (2012). Importancia de la música como medio de comunicación intercultural en el proceso educativo. Teoría de la Educación, 24(2), 107-127. https://doi.org/10.14201/10357

Fisher, M. (2018). Los fantasmas de mi vida. Escritos sobre depresión, hauntología y futuros perdidos. Barcelona, España: Caja Negra.

Freire, P. (1979). Pedagogía del oprimido. Ciudad Autónoma de Buenos Aires, Argentina: Siglo XXI.

Galindo Cáceres, J. (Ed.) (2008). Comunicación, ciencia e historia. Fuentes científicas históricas hacia una comunicología posible. Madrid, España: McGrawHill.

Gil Calvo, E. (2001). Nacidos para cambiar. Cómo construimos nuestras biografías. Barcelona, España: Taurus.

González, D., Gómez Duque, E. y Restrepo, S. M. (2018). Arte y comunicación: experiencias en procesos de memoria del Oriente antioqueño. En C. Arango (Ed.), Territorio, identidades, comunicación (pp. 225-240). Medellín, Colombia: Fondo Editorial Universidad Católica de Oriente.

Gumucio Dagrón, A. (2001). Comunicación y educación: una deuda recíproca. Recuperado de https://www.escritoresyperiodistas.com/NUMER031/alfonso.htm 
Gumucio Dagrón, A. (2016). Comunicación para el cambio social: clave del desarrollo participativo. En J. M. Pereira y A. Cadavid (Eds.), Comunicación, desarrollo y cambio social. Interrelaciones entre comunicación, movimientos ciudadanos y medios (pp. 19-35). Bogotá, Colombia:

Editorial Pontificia Universidad Javeriana.

Hernández Hernández, I. (2018). Grafiti, comunicación alternativa: imaginarios urbanos en el municipio de Rionegro. En C. Arango (Ed.), Territorio, identidades, comunicación (pp. 283-306). Rionegro, Colombia: Fondo Editorial Universidad Católica de Oriente.

Levitin, D. (2019). El cerebro musical. Barcelona, España: RBA.

Maestría en Diseño para la Innovación Social Universidad de Nariño. (2019). Guía de investigación creación. Recuperado de https://madis.udenar.edu.co/category/investigacion

Mejía Betancur, L. P. (2014). El arte como herramienta de comunicación para el cambio social. El caso de Medellín. Folios, (31), 59-74. https://revistas.udea.edu.co/index.php/folios/article/view/326291

Montoya Gallego, L. E. (2018). La calle como escenario de comunicación y como microterritorio urbano: descripción a partir de cinco calles de Rionegro. En C. Arango (Ed.), Desarrollo y territorio: comunidad, familia y educación (pp. 163-186). Medellín, Colombia: Fondo Editorial Universidad Católica de Oriente.

Moral Granada, J. P. (2004). Comunicar la música. Comunicar, 12(23), 13-16. https://doi.org/10.3916/C23-2004-03

Parra Valencia, J. D. (2017). Deconstruyendo el chucu-chucu. Auges, declives y resurrecciones de la música tropical colombiana. Medellín, Colombia: ITM Publicaciones.

Pereira, J. M. (2010). La comunicación: un campo de conocimiento en construcción. Reflexiones sobre la comunicación social en Colombia. Investigación y Desarrollo, 13(2), 412-441. Recuperado de https://www.redalyc.org/pdf/268/26813209.pdf 
Roncallo-Dow, S. (2011). Más allá del espejo retrovisor. La noción de medio en Marshall McLuhan. Bogotá, Colombia: Editorial Pontificia Universidad Javeriana.

Roncallo-Dow, S., Cárdenas, J. D. y Cruz-González, M. C. (2020). Un análisis del discurso de Rogrigo Londoño Echeverri, Timochenco, el 1 de septiembre de 2017 en la Plaza de Bolívar. Izquierdas, 49, 1772-1803. Recuperado de https://intellectum.unisabana.edu.co/handle/10818/45675

Sève, B. (2018). El instrumento musical. Barcelona, España: Acantilado.

\section{Notas}

1 El Oriente antioqueño es una de las nueve subregiones en las que está dividido el departamento colombiano de Antioquia.

2 Para estirar el cuello, y siempre con movimientos suaves y lentos, girar la cabeza de derecha a izquierda varias veces ( 20 segundos a cada lado). Posteriormente, inclinar la cabeza hacia adelante y hacia atrás (20 segundos cada movimiento); por último, inclinar la cabeza a derecha e izquierda. Alinear la oreja derecha con el hombro derecho e intentar que ambos se toquen sin mover los hombros (20 segundos a cada lado).

3 Para estirar la cara, colocar los dedos índices en la comisura de los labios y estirar. Con esta posición, intentar lanzar un beso al aire (15 segundos).

4 Ejercicios de cabeza y cuello: llenar la boca de aire (15 segundos), y después, relajar la cara. Para culminar estos ejercicios, se debe estirar también el diafragma. Con el cuerpo relajado, la respiración normal es diafragmática y se nota porque cuando se inhala el estómago se hincha y cuando se exhala, se deshincha. Se debe, entonces, respirar inhalando todo el aire posible hasta que se infle por completo el estómago, aguantar el aire unos segundos y soltar poco a poco hasta expulsar todo el aire.

5 En el módulo, trabajamos los siguientes tres ejercicios de práctica:

Ejercicio 1. Inspirar profundamente por la nariz. Una vez que los pulmones están llenos de aire, ir soltándolo mediante el sonido «ssss», pronunciando una «ese» tan larga como sea posible.

Ejercicio 2. Inhalar aire y expulsar poco a poco, a través de intervalos pequeños pronunciando el sonido «ts» hasta que se haya expulsado todo el aire.

Ejercicio 3. Extraer todo el aire posible de los pulmones. Luego, respirar hasta hinchar completamente el abdomen y exhalar el aire poco a poco con el sonido «S».

6 En el módulo, se trabajaron los siguientes ejercicios: 
Ejercicio 1. Estirar la boca. Abrirla todo cuanto sea posible durante unos 15 segundos y cerrarla. Repetir dos o tres veces. Con la boca abierta, sin cerrarla, pronunciar todas las vocales; primero de forma corta (a, e, i, o, u); después larga (aaaaaa, eeeee, iiii, ooooo, uuuuu).

Ejercicio 2. Estirar la lengua. Sacar la lengua todo lo que se pueda y llevar la punta hasta el borde del labio superior. Para ejercitar la lengua, probar la lectura de algún párrafo de un texto con cada una de estas dos formas.

Ejercicio 3. Emitir distintos sonidos con escalas musicales. Empezar, por ejemplo, con sonidos nasales como «mmmmm»o «rrrrrrrr», o con las vocales, pero de forma prolongada.

Continuar con el ejercicio, pero emitiendo vocales conjugadas (oa, oa, oa, mi, mi, mi, etcétera).

7 La letra de una canción es simplemente contar algo, el truco reside en que hay diferentes maneras de hacerlo. De acuerdo a lo que se quiera contar se elige un modo que hace que la canción funcione mejor o quede en el olvido. Tomamos, por ejemplo, el tema del amor. El recurso de la primera persona suele ser muy usado en las canciones donde se le habla a una persona, y funciona porque es como si se le susurrara al oído o se lo/a interpelara. La forma descriptiva es más utilizada en las canciones románticas donde se describe cuánto se ama a una persona. La canción en forma de historia tiende a ser más anecdótica, narra un hecho, lo desarrolla en sus detalles y en las emociones que despertó en quien escribió la letra. Por último, una canción tipo consigna puede sintetizar todo en una frase muy poderosa que se utiliza en el estribillo para protestar, para vender un producto o para gritarle algo al mundo. 